\title{
KEMAMPUAN KOSAKATA (KATA DASAR DAN TURUNAN) PADA ANAK USIA 5-6 TAHUN DI PAUD AL-HAIDAR BANDUNG
}

\author{
Syifa Wasilatul Fauziyah ${ }^{1}$, Agus Nero Sofyan ${ }^{2}$ \\ Prodi Linguistik Umum Fakultas Ilmu Budaya Universitas Padjadjaran \\ E-mail: Syifawasilatulfauziyah_unpad@yahoo.com ${ }^{1}$, \\ sofyanagusnero@gmail.com ${ }^{2}$
}

\begin{abstract}
ABSTRAK
This research aims to describe capability of basic vocabulary and derivative vocabulary in children aged 5-6 years old in PAUD Al-Haidar Bandung. The method used is qualitative descriptive research method. The data of this research is every word which formed by children aged 5-6 years old in PAUD Al-Haidar Bandung. The result of this research shows that most children aged 5-6 years old use the basic vocabulary than derivative vocabulary. The reason of it, because children aged 5-6 years old are still in the acquisition stage of how to form a derivative vocabulary (affixation, reduplication, and compound words).

Keywords: basic word, affixation, reduplication, compound words

Penelitian ini berjudul "Kemampuan kosakata (kata dasar dan turunan) pada anak usia 5-6 tahun di PAUD Al-Haidar Bandung. Penelitian ini dilakukan dengan menggunakan metode kualitatif-dskriptif. Data dalam penelitian ini yaitu kata-kata yang di bentuk oleh anak usia 5-6 tahun di paud Al-Haidar Bandung. Hasil analisis dalam penelitian ini yaitu kebanyakan anak usia 5-6 tahun pada umumnya menggunakan kosakata dasar dibandingkan kosakata turunan seperti afiksasi, reduplikasi, dan kata majemuk. Hal yang menyebabkan hal tersebut terjadi dikarenakan anak usia 5-6 tahun masih dalam tahap pemerolehan bagaimana cara membentuk kosakata turunan (afiksasi, reduplikasi dan kata majemuk).
\end{abstract}

Kata kunci: kata dasar, proses afiksasi, pengulangan, pemajemukan.

\section{PENDAHULUAN}

Bahasa merupakan sarana untuk berkomunikasi. Sebagai alat komunikasi, bahasa digunakan untuk menyampaikan gagasan, pikiran, dan ide-ide setiap manusia. Chandler menjelaskan bahwa bahasa merupakan alat komunikasi yang paling sempurna yang dimiliki oleh manusia. Bahasa sebagai alat komunikasi merupakan bagian dari perkembangan manusia yang tidak bisa dipisahkan sebagai alat komunikasi antara sesama (Chandler, 2007). Pada anak, bahasa terus berkembang dari mulai usia dini. Fajriah berpendapat bahwa bahasa memiliki kedudukan penting pola berpikir, sehingga apabila sistem bahasa berbeda maka pola pikirpun akan berbeda, oleh sebab itu bahasa merupakan suatu hal yang sangat penting yang harus dikembangkan 
sejak usia dini. Perkembangan bahasa pada anak sangat berkaitan erat dengan pemerolehan bahasa pada anak (Fajriah, 2015). Anak memperoleh bahasa tidak akan lepas dari kosakata. Penting bagi seorang anak untuk mempelajari dan menguasai kosakata karena keterampilan berbahasa seorang anak akan meningkat bila kualitas kosakata seorang anak meningkat. Perluasan kata pada anak lebih ditekankan kepada kosa katanya. Dalam hal ini, Monks dalam Herlina menjelaskan bahwa keterampilan berbahasa pada anak ini sangatlah penting, mulai dari satu kata, dua kata, lambat laun akan terus berkembang sehingga menjadi sebuah kalimat, dan dari perkembangan itulah kehidupan berbahasa anak dibentuk menjadi anak yang memiliki kecerdasan linguistik yang baik (Herlina, 2016).

Penelitian ini dilakukan di PAUD AL-HAIDAR Bandung. Kemampuan bahasa anak usia 5-6 tahun menarik untuk dikaji karena anak usia 5-6 tahun perkembangannya telah mencapai tingkat yang semakin baik dan sempurna anak telah memiliki pembendaharaan kosa kata yang kaya. Anak usia 5-6 tahun memiliki daya serap yang tinggi atas kata-kata yang diperolehnya berbagai macam kosa kata atau istilah-istilah baru bagi seorang anak, dapat meningkatkan kemampuan berbahasa seorang anak. berdasarkan hal-hal yang telah dideskripsikan tersebut penlitian ini akan membahas atau mendeskripsikan kemampuan kosakata (kata dasar dan kata turunan) pada anak usia 5-6 tahun di PAUD Al-Haidar Bandung.

\section{KAJIAN TEORITIK}

\section{Pemerolehan Bahasa}

Pemerolehan bahasa (language acquisition) merupakan proses-proses yang berlaku di dalam otak seorang anak ketika memperoleh bahasa ibunya. Cristofaro berpendapat bahwa peran ibu dan peran lingkungan sangatlah penting dalam perkembangan dan pemeroehan bahsa anak, karena anak mempelajari dengan cara menyerap bahasa dari lingkungan ia hidup. Pemerolehan bahasa pada anak terjadi pada otak anak-anak ketika memperoleh bahasa pertama dari ibunya. Dalam hal ini Cristofaro berpendapat bahwa bahsa ibu sangatlah berpengaruh terhadap kemampuan atau perkembangan kosakata seorang anak (Cristofaro and Lemonda, 2011).

Ketika bahasa pertama anak telah sempurna anak akan mempelajari bahasa kedua. Misalnya, seorang anak memiliki bahasa ibu bahasa Sunda. dan biasanya anak akan mempelajari bahasa keduanya yaitu bahasa Indonesia ketika memasuki sebuah lingkungan pendidikan. Chaer menjelaskan bahwa pemerolehan bahasa pada anak itu berkenaan pada bahasa pertama sedangkan bahasa kedua merupakan pembejalaran bagi anak (Chaer, 2014). Dalam hal ini, 
Kemampuan Kosakata pada Anak

Syifa \& Agus

pemerolehan bahasa ini yaitu

hanyalah kata tanpa sebuah arti bagaimana manusia dapat (Wright, 2014).

mempersepsi dan kemudian memahami ujaran orang lain yang merupakan unsur pertama yang harus dikuasai oleh manusia dalam berbahasa (Dardjowidjojo, 2003). Pemerolehan bahasa pada anak merupakan proses manusia mendapat kemampuan untuk menangkap, menghasilkan dan menggunakan kosakata untuk pemahaman dan komunikasi.

Kosakata merupakan suatu hal yang paling penting bagi pemerolehan bahasa pada anak. Penting bagi seorang anak untuk mempelajari sebuah kosa kata karena keterampilan berbahasa seorang anak akan meningkat bila kualitas kosakata seorang anak meningkat. Perluasan kata pada anak lebih ditekankan kepada kosa katanya. Dalam hal ini, Monks dalam Herlina menjelaskan bahwa keterampilan berbahasa pada anak ini sangatlah penting, mulai dari satu kata, dua kata, lambat laun akan terus berkembang sehingga menjadi sebuah kalimat, dan dari perkembangan itulah kehidupan berbahasa anak dibentuk menjadi anak yang memiliki kecerdasan linguistik yang baik (Herlina, 2016). Hal ini selaras dengan Neuman yang berpendapat bahwa sangat tidak mungkin seorang anak dapat membaca atau memahami bacaan tanpa pondasi kosakata yang kuat, tanpa pengetahuan kosakata, kata

\section{Kata Dasar dan Kata Turunan}

Kata dasar menurut Chaer yaitu sebuah satuan bebas yang dapat berdiri sendiri, dan terjadi dalam morfem tunggal, contohnya seperti pergi, rumah, buku. Jadi sebuah kata dasar ini merupakan sebuah kata yang dapat berdiri sendiri dan dapat membentuk sebuah makna yang utuh (Chaer, 2014).

Proses afiksasi ini merupakan proses pembubuhan kata yang yang dilakukan dengan cara membubuhkan morfem terikat pada bentuk kata dasar. Samsuri membagi proses afiksasi ini menjadi beberapa bagian, yaitu prefiksasi, sufiksasi, infiksasi, dan konfiksasin (Samsuri, 1987).

1. Prefiksasi merupakan proses pembubuhan afiks (morfem terikat) yang ditempatkan di depan bentuk dasar. Contohnya bermain, tertawa, bernyanyi, membawa.

2. Sufiksasi merupakan proses pembubuhan afiks di akhir bentuk dasar. Contohnya: baca-kan, bawakan, kena-i, serang-an.

3. Infiksasi merupakan proses pembubuhan afiks ditengah bentuk dasar. Pembubuhan afiks ini ditulis serangkai dengan kata dasarnya sebagai satu kesatuan. Contohnya gemetar (g-em-etar), gerigi (g-er-igi), kinerja (k-in-erja).

4. Konfiksasi merupakan proses pembubuhan afiks diawal dan akhir bentuk kata dasar. Contohnya: 
dibacakan

membelikan

(di-baca-kan), (mem-beli-kan),

menceritakan (men-cerita-kan).

Proses pengulangan kata merupakan proses pembentukan kata dengan mengulang satuan bahasa baik secara keseluruhan, sebagian, maupun disertai dengan perubahan bunyi.

1. Pengulangan penuh merupakan pengulangan seluruh bentuk dasar, tanpa perubahan fonem dan tidak berkombinasi dengan pembubuhan afiks. Contohnya: rumah-rumah, mobil-mobil.

2. Pengulangan sebagian merupakan pengulangan sebagian dari bentuk dasar sebuah kata, yang diulang ialah suku pertama dari bentuk-bentuk tersebut. Contohnya: pepohonan, lelaki.

3. Pengulangan dengan modifikasi merupakan pengulangan yang disertai dengan perubahan satu fonem atau lebih dari bentuk dasar tersebut. Contohnya: sayur-mayur, superduper.

Kata turunan yang akan dibahas dalam penelitian ini, selain proses afiksasi dan pengulangan kata, kata majemuk akan di bahas dalam penelitian ini. Samsuri menjelaskan bahwa keta majemuk ini merupakan konstruksi yang terdiri atas dua morfem atau dua kata atau lebih yang mempunyai suatu pengertian (Samsuri, 1987). Jadi, kata majemuk ini merupakan gabungan dari morfem dasar yang seluruhnya berstatus sebagai kata yang mempunyai makna yang baru. Contohnya sabun mandi, rumah sakit, dan kaki tangan. Selain itu, salah catu ciri kata majemuk yaitu tidak bisa disisipkan, dari contohcontoh diatas tidak bisa disisipkan menjadi sabun yang mandi, rumah yang sakit, atau kakinya tangan.

\section{METODOLOGI PENELITIAN}

Penelitian mengenai kemampuan kosakata pada anak usia 5-6 tahun ini menggunakan rancangan penelitian deskriptif kualitatif. Dalam hal ini, metode deskriptif merupakan metode yang digunakan untuk mendeskripsikan, yaitu membuat penjelasan atau menggambarkan secara faktual, sistematis, dan akturat mengenai data, sifat-sifat dan hubungan fenomena-fenomena yang diteliti, selain itu metode kualitatif merupakan prosedur yang menghasilkan sebuah data baik itu data tertulis ataupun data lisan (Dawson, 2002).

Untuk memperoleh data dalam penelitian ini, peneliti menggunakan metode simak dengan menggunakan teknik lanjutan simak libat bebas cakap. Teknik lanjutan simak libat bebas cakap merupakan metode yang dilakukan dengan tidak terlibat dalam dalam dialog atau wawancara jadi peneliti tidak ikut serta dalam proses pengambilan data (Sudaryanto, 2015). Karena data berbentuk tulisan yaitu kosakata-kosakata yang dibentuk oleh anak usia 4-5 tahun di PAUD Al-Haidar, tulisan-tulisan tersebut merupakan surat-surat yang 
diberikan oleh anak-anak PAUD AlHaidar kepada guru-guru mereka. Setelah teknik tersebut dilakukan, penulis menganalisis data menggunakan metode agih.

Metode agih memiliki teknik dasar yang disebut dengan teknik bagi unsur langsung (BUL) yaitu memilah data berdasarkan satuan lingual menjadi beberapa bagian atau unsur (Sudaryanto, 2015)..

\section{HASIL DAN PEMBAHASAN}

Anak usia 5-6 tahun di PAUD Al-Haidar Bandung, penulis memperoleh beberapa kata dasar dan imbuhan (afiksasi) yaitu sufiks, prefiks, pengulangan kata, dan pemajemukan kata.

\section{Data 1 (Anak Ti):}

"ibu baik sekali ibu puri sama ibu dewi baik banget dan sama ibu haji sama ibu erna dan sama ibu sipa sama ibu iin baik sekali. ibu dewi terimakasih sama ibu puri terimakasih ibu-ibu semua udah ajari aku".

Pada data tersebut, Ti yang berumur 6 tahun terlihat lebih banyak memiliki pembendaharaan kosakata dasar yang berupa nomina dan adjektiva, contohnya pada kata, ibu, guru, baik, cantik. Pada tulisan Ti ini, terdapat kosakata dasar yang berimbuhan pada akhir kata yaitu akhiran $-i$ dalam kosakata ajari. Ti telah mulai melakukan pengulangan kata, dengan menuliskan kata $i b u-i b u$ yang termasuk pengulangan secara penuh dengan makna para ibu-ibu. Pemajemukan mulai digunakan meskipun hanya dalam satu kosakata yaitu terima kasih. Dalam tulisannya, Ti ini cenderung menuliskan kata dasar dibandingkan kata turunan lainnya karena memang $\mathrm{Ti}$ yang berumur 6 tahun ini memiliki cukup banyak akan pembendaharaan kosa kata sebagaimana Haryani dan Rahmat yang berpendapat bahwa pembendaharaan kosakata yang cukup banyak merupakan suatu hal yang sangat penting demi kelancaran komunikasi (Haryani \& Rahmat, 2014), namun Ti masih dalam tahap pembelajaran bagaimana cara membentuk sebuah kata turunan seperti kata berimbuhan, oleh sebab itu, dalam tulisannya ini ia banyak melakukan penulisan kata dasar.

\section{Data 2. (Anak Ap):}

"guru tersayang - bu dewi baik latihan-bu puri baik - ap sayang semuanya yang baik sekolahnya - bu erna - bu haji - ayang bu sipa".

Pada data tersebut, Ap yang berumur 6 tahun terlihat lebih banyak memiliki pembendaharaan kosakata dasar yang berupa nomina, dan ajektif misalnya, baik, sekolah, saya, ibu, guru, baik, cantik. Dalam hal ini, Dardjowijoljo menjelaskan pada umumnya anak menguasai nomina lebih awal dan lebih banyak dari pada verba. Pada tulisan Ap ini, terdapat kosa kata berimbuhan, pada awal kata dasar dan pada akhir kata dasar (Dardjowidjojo, 2003).

Pada awal kata dasar yaitu dalam kosakata ter-sayang yang berasal dari kata sayang, sedangkan imbuhan 
pada akhir kata dasar yaitu akhiran an dalam kata latihan. Dalam tulisannya, Ap banyak melakukan pengulangan, namun, pengulangan disini bukanlah pengulangan yang memiliki makna, pengulangan yang Ap tuliskan sepertinya berupa penegasan agar pembaca dapat mengerti apa yang Ap tuliskan dan dalam tulisan Ap, tidak ditemukan kosakata majemuk. Ap ini, lebih cenderung menuliskan kata dasar dibandingkan kosa kataturunan, karena Ap yang berumur 6 tahun ini masih dalam tahap pembelajaran bagaimana cara menuliskan sebuah kata turunan dengan baik dan benar.

\section{Data 3(Anak Ma):}

"ibu puri dan ibu Dewi - ibu puri nanti jangan lupakan ma dan ke dan semuanya"

Pada data tersebut, Ma yang berumur 6 tahun banyak memiliki pembendaharaan kosakata dasar yang berupa nomina misalnya, pada kata ibu, Ma, Puri, Dewi. Pada tulisan Ma terdapat kosakata berimbuhan, yaitu imbuhan pada akhir kata dasar dalam kosakata latihan yang berasal dari kata latih+an dan kata lupakan yang berasal dari kata lupa+kan. Dalam tulisan Ma ini, tidak ditemukan kosakata pengulangan dan pemajemukan. Ma tebih cenderung menuliskan kosakata dasar dibandingkan kata turunan, karena Ma yang berumur 6 tahun ini masih dalam tahap pembelajaran bagimana cara membentuk sebuah kata turunan yang baik, oleh sebab itu dalam tulisannya Ma lebih cenderung menggunakan kata dasar.

\section{Data 4 (Anak Ke):}

"ibu makasih sudah mengajari kita ke ma, ka dan Ke".

Pada data tersebut, Ke yang berumur 5 tahun banyak memiliki pembendaharaan kosakata yang berupa kata benda, yaitu dalam kata ibu, kita, Ma, Ke, dan Ka. Dalam tulisan Ke ini, terdapat kosakata berimbuhan, yaitu imbuhan awal dan akhir pada sebuah kosakata dasar, dalam kata mengajari yang berasal dari kata ajar+i. Ke banyak menuliskan pengulangan, namun, pengulangan disini bukanlah pengulangan yang memiliki makna, pengulangan yang $\mathrm{Ke}$ tuliskan sepertinya berupa penegasan agar pembaca dapat mengerti apa yang $\mathrm{Ke}$ tuliskan. Pada tulisan Ke, terdapat kosakata majemuk yaitu kata terima kasih. Ke yang berumur 5 tahun ini lebih banyak menuliskan kosakata dasar karena Ke masih dalam tahap pemerolehan atau pembelajaran bagaimana cara membentuk sebuah kata turunan, oleh sebab itu, dalam tulisannya ini $\mathrm{Ke}$ cenderung menuliskan kata dasar.

\section{Data 5 (Anak Na):}

"guruku aku sayang ibu guru karena bu guru sangat baik"

Pada data 5, Na yang berumur 5 tahun lebih cenderung memakai kosakata dasar seperti kata benda dan kata sifat, misalnya, kata guruku, aku, ibu, sayang, baik. Dalam tulisan $\mathrm{Na}$ 
Kemampuan Kosakata pada Anak

Syifa \& Agus

ini, tidak terdapat kosakata yang berimbuhan, begitupula dengan kata pengulangan dan pemajemukan, $\mathrm{Na}$ masih belum menggunakannya. Dalam tulisan Nazla ini, ia lebih banyak menuliskan kata dasar, diabndingkan dengan kosakata yang berimbuhan. . Na yang berumur 5 tahun ini masih dalam tahap pemerolehan dan pembelajaran bagaimana cara menuliskan sebuah kata turunan yang baik dan benar.

\section{Data 6 (Anak Fa):}

"ibu puri bu dewi bu erna bu haji cantik teh sipa tersayang ibu tersayang terimakasih"

Pada data $6, \mathrm{Fa}$ yang berumur 6 tahun banyak memiliki pembendaharaan kosakata yang berupa kata dasar $\mathrm{Fa}$ lebih banyak menggunakan kata benda dan kata sifat mislanya, ibu dan cantik. Pada tulisan Fa terdapat kosakata yang berimbuhan, imbuhan pada awal kata dasar, yaitu kata ter+sayang yang menjadi kosakata tersayang.

Dalam bentuk pengulangan kata, Fa masih belum membentuk atau menggunakan pengulangan kata, begitu pula dengan kata majemuk. Fa lebih cenderung menggunakan kosakata dasar pada tulisannya dibandingkan kata turunan lainnya. Ia memiliki pembendaharaan kosa kata dasar yang lebih banyak dibandingkan dengan kosakata turunan dalam tulisannya.

\section{Data 7 (AnakAd):}

"ibu puri bu dewi bu erna bu haji cantik teh sipa tersayang ibu tersayang terimakasih"

Pada data 7, Ad yang berumur 6 tahun lebih cenderung menggunakan kosakata dasar dibandingkan kosakata yang berimbuhan. Dalam tulisannya kosakata dasar yang ia bentuk yaitu berupa kata benda, dan kata sifat misalnya, ibu, cantik, Dewi, Erna, Puri. Dalam tulisan Ad ini, terdapat kosakata berimbuhan, yaitu imbuhan pada awal kata dasar, pada kata ter+sayang yang menjadi sebuah kata tersayang, sedangkan untuk bentuk pengulangan kata, Ad belum menuliskan pengulangan yang memiliki makna, pengulangan yang Ad tuliskan sepertinya berupa penegasan agar pembaca dapat mengerti apa yang ia tuliskan dan untuk pemajemukan Ad telah mampu membentuk kata majemuk, meskipun hanya satu kata yaitu kata terima kasih yang merupakan kata majemuk. Dalam tulisan Ad ini lebih banyak terdapat kata dasar dibandingkan dengan kata turunan lainnya.

\section{Data 8 (Anak Re):}

"ibu guru yang baik saya sayang ibu terima kasih ibu saya bisa pandai".

Pada data 8, Re yang berumur 5 tahun lebih cenderung menggunakan kosakata dasar dibandingkan kosakata yang berimbuhan. Kosakata dasar yang ia bentuk pada umumnya berupa kata benda dan ajektif misalnya, ibu, guru, baik, pandai. Pada tulisan Re ini tidak ditemukan 
kosakata berimbuhan. Dalam tulisan Re pun tidak ditemukan pengulangan kata, Re belum melakukan pengulnagan kata meskipun dalam bentuk pengulangan secara penuh, kemudian dalam tulisan $\mathrm{Re}$ ini, terdapat sebuah kata majemuk, yaitu terima kasih meskipun hanya satu kata. Re yang berumur 6 tahun ini lebih banyak menuliskan kosa kata dasar di bandingkan yang berimbuhan, pengulangan atau pemajemukan.

\section{Data 9 (Anak Ga):}

"ibu dewi udah baik sekali sama ibu puri sama ibu erna sama ibu haji sama ibu sipa sama ibu iin baik sekali udah ajari aku ibu di paud al-haidar baik sekali aku sayang sama ibu dewi, ibu puri, ibu iin, ibu sipa dan ibu haji yang di paud alhaidar ibu guru yang baik"

Pada data 9, Ga yang berumur 5 tahun lebih cenderung menggunakan kosakata dasar dibandingkan kosakata yang berimbuhan, pengulangan atau pemajemukan. Kosakata yang ia tulis pada umumnya berupa kata benda dan ajektif, misalnya, ibu, dewi dan baik. Pada tulisan $\mathrm{Ga}$ ini ditemukan kosa kata berimbuhan, meskipun hanya satu kosakata yaitu pada kata ajari (ajar+i). Dalam tulisannya, Ga banyak melakukan pengulangan, namun, pengulangan yang $\mathrm{Ga}$ lakukan ini bukanlah sebuah kata pengulangan yang memiliki sebuah makna, tetapi pengulangan yang $\mathrm{Ga}$ tuliskan, berupa penegasan agar pembaca dapat mengerti atau memahami apa yang $\mathrm{Ga}$ tuliskan, kemudian $\mathrm{Ga}$ tidak menuliskan sebuah kosa kata majemuk. Ga ini lebih cenderung menuliskan kosakata dasar dibandingan dengan kosa kata turunan.

\section{Data 10 (Anak Ka):}

"ibu dewi sayang - ibu erna sayang ibu haji sayang".

Pada data 10, Ka yang berumur 6 tahun ini lebih banyak menuliskan kosakata dasar dibandingkan kosakata turunan seperti kosa kata berimbuhan, pengulangan kata atau pemajemukan kata. Kosakata dasar yang Ka tuliskan pada umumnya berupa kata benda dan ajektif seperti ibu, erna, dewi, sayang. Dalam tulisan kasrini, tidak ditemukan kata turunan baik itu berupa pembubuhan afiks, prefiks, sufiks, konfiks, kata pengulangan atau kata majemuk. Dalam tulisannya $\mathrm{Ka}$ menuliskan pengulangan, namun pengulangan yang Ka tuliskan bukan berupa pengulangan kata yang dapat menghasilkan makna, pengulangan yang $\mathrm{Ka}$ tuliskan ini berupa penegasan agar pembaca dapat memahami atau mengerti apa yang Ka tuliskan. Dalam tulisannya ini Kasrini cenderung menuliskan kata dasar dibandingkan kata turunan.

\section{Data 11 (AnakNa):}

"ibu tersayang - teh sipa tercinta - ibu dewi cantik - ibu erna cantik - ibu haji baik sekali".

Pada data 11, Na yang berumur 5 tahun ini lebih banyak menuliskan kata dasar dibandingkan dengan kata 
Kemampuan Kosakata pada Anak

Syifa \& Agus

turunan. Kata dasar yang Na tuliskan ini umumnya berupa kata benda dasn ajektif misalnya, ibu, Dewi, Sipa, baik, dan cantik. Dalam tulisan $\mathrm{Na}$ terdapat sebuah kata berimbuhan yang diberi imbuhan di awal kata dasar yaitu pada kata tercantik $($ ter + cantik) dan tercina (ter+cinta). Dalam tulisan $\mathrm{Na}$, tidak terdapat sebuah pengulangan kata yang memiliki makna, $\mathrm{Na}$ melakukan sebuah pengulangan kata, tetapi pengulangan yang $\mathrm{Na}$ lakukan ini sepertinya hanya untuk penegasan agar pembacanya mengerti atau memahami apa yang $\mathrm{Na}$ tuliskan, kemudian dalam tulisannya tidak ditemukan sebuah kata majemuk. $\mathrm{Na}$ lebih cenderung menuliskan kata dasar dibandingkan kata turunan.

\section{Data 12 (Anak Ha):}

"ibu guru aku sayang ke ibu puri dan ibu dewi terimakasih karna sudah mengajar".

Pada data 12, Ha yang berumur 6 tahun lebih cenderung menggunakan kosakata dasar dibandingkan kata turunan. Kata dasar yang Ha tuliskan ini pada umumnya berupa kata benda misalnya, ibu, guru, Puri, Dewi, kemudian dalam tulisan Ha terdapat sebuah kata berimbuhan yaitu imbuhan pada awal kata dasar pada kata mengajar (meng+ajar). Dalam tulisan $\mathrm{Ha}$ tidak terdapat sebuah pengulangan kata, baik itu secara penuh maupun sebagian, kemudian dalam tulisan Ha terdapat sebuah kata majemuk meskipun hanya satu yaitu pada kata terima kasih. Ha cenderung menuliskan kosakata dasar, dibandingkan kosakata turunan seperti seperti kata berimbuhan, pengulangan atau pemajemukan.

\section{Data 13 (Anak Fi):}

"ibu terbaik - ibu dewi cantik, ibu puri cantik - aku senang belajar di paud alhaidar - terima kasih sudah mengajari aku."

Pada data 13, Fi yang berumur 6 tahun ini, lebh banyak menuliskan kosakata dasar dibandingkan kosakata turunan. Pada tulisannya Fi lebih banyak menggunakan kata dasar yang berupa kata benda dan ajektif misalnya, ibu, dewi, senang, puri.

Dalam tulisan Fi terdapat beberapa kosakata berimbuhan yaitu kata belajar (be+ajar) kemudian kata mengajari (meng+ajar+i) dalam tulisan Fi ini, tidak ditemukan pengulangan kata, kemudian untuk kata majemuk Fi sudah mulai menggunakannya meskipun baru satu kata yaitu pada kata terima kasih. Dalam tulisan Fi ia lebih cenderung menggunakan kata dasar dibandingkan kata turunan, seperti seperti kata berimbuhan, pengulangan atau pemajemukan. Di bawah ini merupakan kemampuan kosakata dasar dan imbuhan pada anak usia 56 tahun yang tercatat dalam sebuah tabel: 
Tabel 1. Kemampuan kosakata dasar dan imbuhan anak usia 5-6 tahun

\begin{tabular}{|c|c|c|c|c|c|c|c|c|}
\hline \multirow[b]{2}{*}{ Nama } & \multirow[b]{2}{*}{ usia } & \multirow[b]{2}{*}{$\begin{array}{c}\text { Kosakata } \\
\text { dasar }\end{array}$} & \multicolumn{6}{|c|}{ Kosakata beriunbuhan } \\
\hline & & & Prefiks & $\begin{array}{c}\text { Sufik } \\
s\end{array}$ & infiks & Konfiks & Pengulangan & $\begin{array}{c}\text { Kata } \\
\text { Majemuk }\end{array}$ \\
\hline Ti & 6th & 34 & - & 1 & - & - & 1 & 1 \\
\hline Ap & 6th & 18 & 1 & 1 & & & & \\
\hline Ma & 6th & 13 & & 2 & & & & 1 \\
\hline $\mathrm{Ke}$ & 5th & 9 & & & & 1 & & 1 \\
\hline $\mathrm{Na}$ & 5th & 9 & & & & & & \\
\hline Fa & 6th & 12 & 1 & & & & & \\
\hline Ad & 6th & 12 & 1 & & & & & \\
\hline $\operatorname{Re}$ & 5th & 11 & & & & & & \\
\hline Ga & 5th & 45 & & 1 & & & & \\
\hline Ka & 6th & 12 & & & & & & \\
\hline $\mathrm{Na}$ & 5th & 13 & 2 & & & & & \\
\hline На & 5th & 12 & 1 & & & & & 1 \\
\hline Fi & 6th & 15 & 1 & & & 1 & & 1 \\
\hline
\end{tabular}

Dalam tabel diatas terlihat bahwa kemampuan kosakata dalam menuliskan kosakata berbeda-beda. Pembendaharaan kosakata yang dimiliki, dari segi usia anak-anak yang berumur 6th lebih banyak dibandingkan anak-anak yang berusia 5th. Kosakata yang diperoleh pada umumnya ialah kosakata dasar. Jika merujuk pada teori Yule beliau menjelaskan bahwa perkembangan dan pemerolehan kosakata pada anak ini akan lebih mengacu pada kosakata dasar, seperti yang berupa nomina(kata benda), verba (kata kerja), dan adjektiva (kata sifat) (Yule, 2010). Dalam penelitian ini ragam kosakata dasar yang diperoleh ini pada umumnya mempunyai kelas kata nomina, verba dan adjektiva.

\section{KESIMPULAN}

Hasil penelitian kemampuan kosakata (kata dasar dan kata turunan) pada anak usia 5-6 tahun ini pada umumnya berkembang dengan cara mereka menuliskan surat untuk guru mereka yang mengungkapkan perasaan mereka terhadap gurunya.
Dalam tulisannya anak lebih cenderung menggunakan kosakata dasar. Kemudian ragam kosakata dasar yang diperoleh ini pada umumnya mempunyai kelas kata nomina, verba dan adjektiva.

\section{DAFTAR PUSTAKA}

Chaer, A. (2014). Linguistik Umum. Jakarta: PT Rineka Cipta.

Chandler, D. (2007). Semiotics The Basic.

Cristofaro and Lemonda. (2011). Mother-Child conversations at 36 months and at pre-kindergarten: Relations to Children's school readiness. Journal of Early Childhood Literacy.

Dardjowidjojo, $\mathrm{S}$.

(2003). Psikolinguistik: Pengantar Pemerolehan Bahasa Manusia.

Dawson, C. (2002). Practical Research Methods.

Fajriah, J. (2015). Peningkatan Penguasaan Kosakata Bahasa Arab (Mufradat) Melalui Penggunaan Media Kartu Kata Bergambar. Jurnal Pendidikan Usia Dini, 9.

Haryani, \& Rahmat. (2014). Pengaruh Media Kartu Kata Terhadap Kemampuan Membaca Dan Penguasaan Kosakata. Jurnal Pendidikan Usia Dini, 8.

Herlina. (2016). Pemerolehan Fonology Pada Anak Usia Dua Tahun Dua Bulan. Jurnal Pendidikan Usia Dini, 10.

Samsuri. (1987). Analisis Bahasa.

Sudaryanto. (2015). Metode dan Aneka Teknik Analisis Bahasa.

Wright, N. and. (2014). The Magic of Words: Teaching Vocabulary in The Early Childhood Classroom. American Educator.

Yule, G. (2010). The Study of Language. 